\title{
THE TOXIC EFFECTS OF UREA ON NORMAL INDIVIDUALS *
}

A. W. HEWLETT, M.D., Q. O. GILBERT, M.D.

AND

A. D. WICKETT, M.D.

ANN ARBOR, MICH.

In order to throw light on the nature of uremia, many investigators have studied the physiologic effects produced when urea is administered to or injected into animals. The majority of those who have undertaken such studies were unable to demonstrate that urea acted as a poison. Only a few have succeeded in producing definite toxic effects. For example, Herter and Wakeman, ${ }^{1}$ as well as Marshall and Davis, ${ }^{2}$ found that approximately 1 per cent. of the body weight must be injected into animals in order to produce a fatal result. Ascoli, ${ }^{3}$ in reviewing the earlier literature, has sought to explain the occasional toxic effects observed on one or more of the following assumptions: (1) the urea used was not pure, (2) it was injected intravenously in too concentrated a solution, or (3) where used in dilute solution the effects were attributable to the excessive amounts of liquid rapidly introduced into the body. Under any circumstances it is clear that in animal experiments definite toxic effects can be produced only when extraordinarily large doses of the drug were given, doses which presumably raise the concentration of urea in the body above that which is encountered in most cases of uremia in man. For these reasons the view has become generally accepted that the toxic effects of urea in any concentration encountered in patients are negligible and that the symptoms of uremia are due to the action of the other and more poisonous substances.

Recent advances in our knowledge concerning the toxic symptoms presented by patients in the more advanced stages of nephritis permit one, however, to approach this question from a new point of view. It seems established that uremia, in the sense of any toxic state com-

* Submitted for publication June 12, 1916.

* From the Department of Internal Medicine, University of Michigan.

1. Herter, C. A., and Wakeman, A. J.: On Alterations in the Composition of the Blood Resulting from Double Nephrectomy, Jour. Exper. Med., 1899, iv, 117 .

2. Marshall, E. K., Jr., and Davis, D. M.: Urea: Its Distribution in and Elimination from the Body, Jour. Biol. Chem., 1914, xviii, 53.

3. Ascoli, G.: Vorlesungen über Urämie, Jena, 1903, p. 130. 
plicating renal disease, includes a variety of distinct conditions. In certain patients, toxic symptoms occur when the urea and the total incoagulable nitrogen of the blood are either not increased or are increased to such a small extent that the symptoms observed can hardly be attributed either to the urea or to an increase in the total incoagulable nitrogen of the blood. This appears to be particularly true of those cases of uremia in which generalized epileptiform convulsions dominate the symptomatology. In such cases particularly, the search for a specific toxic substance seems indicated, and N. B. Foster ${ }^{4}$ has reported the isolation of a toxic base from the blood of patients suffering from the convulsive form of uremia.

On the other hand, it has been shown that during the later stages of nephritis there is not infrequently an increase of urea and of other nitrogenous substances, such as uric acid, creatin, creatinin, and indican in the blood and that when this increase becomes very marked toxic symptoms are present. In such patients the urea not only shows the greatest absolute increase, but its increase is relatively greater than the increase in the sum total of the other nonprotein nitrogenous bodies. Clinical studies have demonstrated furthermore that such patients frequently do not present certain of the classic uremic symptoms. Generalized convulsions, paralyses and prolonged comas are often absent. The symptoms which characterize the advanced stages of nitrogenous retention have been for some years the subject of study, particularly by French clinicians. According to Widal, ${ }^{5}$ for example, the symptoms consist of loss of appetite, fatigue, prostration, mental dulness, somnolence and eventually coma. Reiss, ${ }^{6}$ who has recently described this condition as the asthenic type of uremia, believes that it is characterized clinically by drowsiness and indifference, by bodily fatigue and prostration, and by sudden cardiac death without prolonged coma.

The modern blood studies on nephritic patients have also served to define the relation that exists between the clinical symptoms and the level of urea and nonprotein nitrogen in the blood. While it is diffcult, by reason of individual variations, to fix accurately the level at which the accumulation of nitrogenous waste products leads to the production of symptoms, nevertheless one may say in general that symptoms characteristic of asthenic uremia are rarely well defined when the concentration of urea in the blood is less than $100 \mathrm{mg}$. per

\footnotetext{
4. Foster, N. B.: The Isolation of a Toxic Substance from the Blood of Uremic Patients, Tr. Assn. Am. Phys., 1915, xxx, 305.

5. Widal, F., and Lemierre, A.: Die diätetische Behandlung der Nierenentzündungen, Ergebn. d. inn. Med. u. Kinderh., 1909, iv, 523.

6. Reiss, E.: Zur Klinik und Einteilung der Urämie, Ztschr. f. klin. Med., 1914, Ixxx, 97, 424, 452.
} 


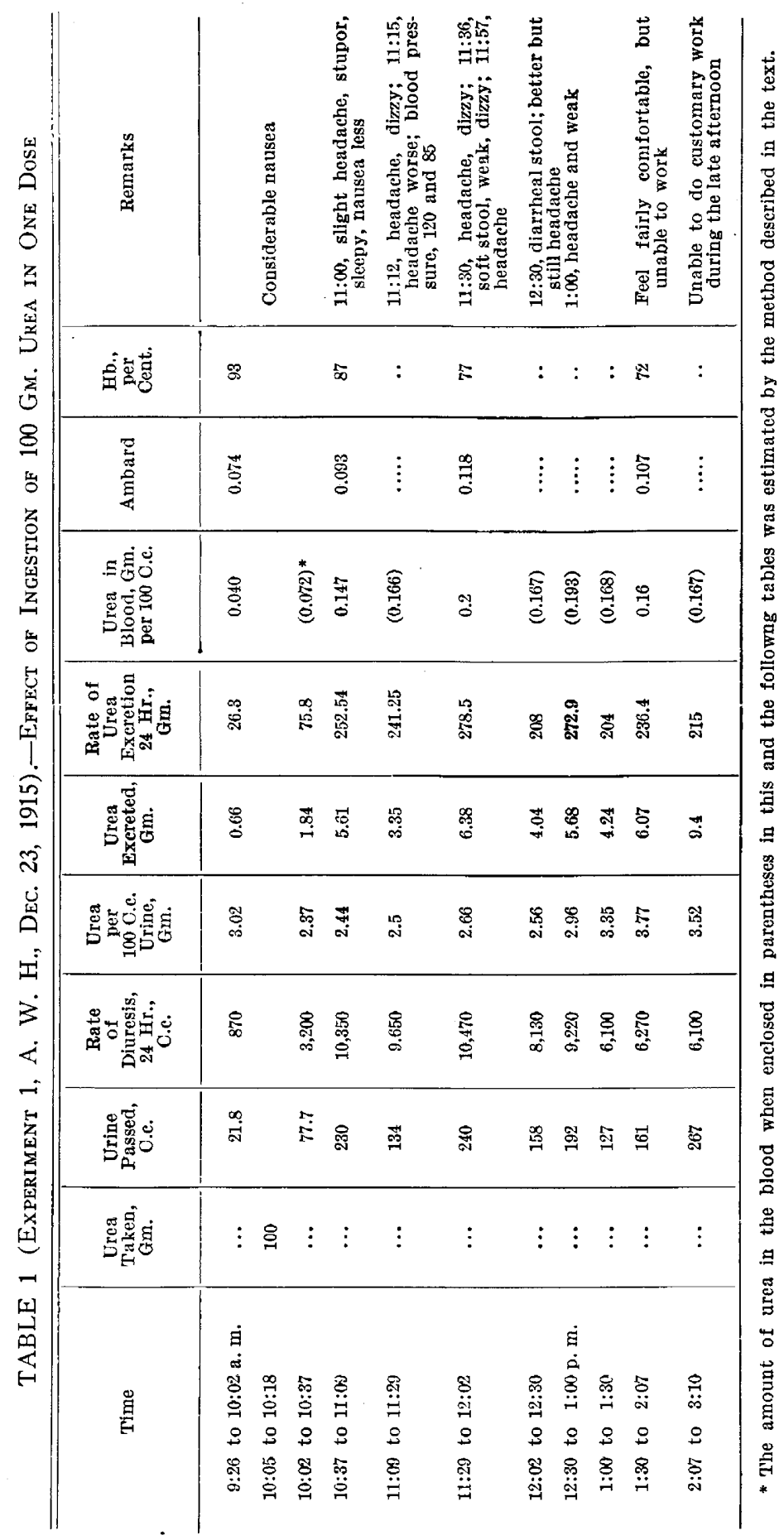


100 c.c. of blood and that they are rarely absent when the concentration exceeds $200 \mathrm{mg}$. From clinical observations, therefore, one would be inclined to place the point at which the accumulation of urea might possibly cause symptoms between the two limits of 100 and $200 \mathrm{mg}$. of urea per 100 c.c. of blood.

The bodily and mental prostration which characterizes the earlier stages of asthenic uremia may readily escape detection in animal experiments. For this reason it seemed a matter of some importance tc study once again the toxic effects of this compound, using men as the subjects of the study. Our experiments were therefore undertaken with the view of ascertaining whether normal persons manifest toxic symptoms when sufficient urea has been taken by mouth to raise the urea in the blood to the levels encountered in asthenic uremia. Since urea diffuses rapidly from the blood into the tissues, it is evident that in order to attain such concentrations in the blood large quantities of urea must be given. Furthermore, since urea is rapidly eliminated from the body by way of the urine, it is evident that the large quantity of urea must be taken within a brief period of time and that prolonged experiments can be carried out only with considerable difficulty. As will appear in the following experiments, the ingestion of $100 \mathrm{gm}$. of urea within a few hours raises the level of blood urea in a normal individual to from 150 to $245 \mathrm{mg}$. per 100 c.c. Such concentrations are comparable with those encountered in the asthenic type of uremia and if the symptoms in the latter condition are in any way dependent on the concentration of urea in the blood and tissues, symptoms should occir under the conditions of our experiment.

Outline of Experiments: Five experiments were performed, four on the authors themselves and one on Dr. F. N. Wilson, who volunteared for this purpose. The subject of the experiment presented himself to the clinical laboratory after his usual breakfast and emptied his bladder. The urea content of his blood was determined and this was compared with the output of urea in the urine by the method of Ambard. ${ }^{\top}$ The subject then took the urea dissolved in water, either in a single dose or in doses divided over a period of from three to six hours. In three instances the intake was completed before the noon meal, while in two others one or more doses were taken after the meal. The successive specimens of urine were collected, measured and analyzed for urea, over a period varying from nine to thirty hours after the beginning of the experiment. The concentration of urea in the blood and the Ambard coefficient were determined on two or more occasions during the afternoon of the experimental day and

7. Ambard, L., and Weill, A.: Les lois numeriques de la sécrétion rénale de l'urée et du chlorure de sodium, Jour. physiol. et pathol. géner., 1912, xiv, 753. 


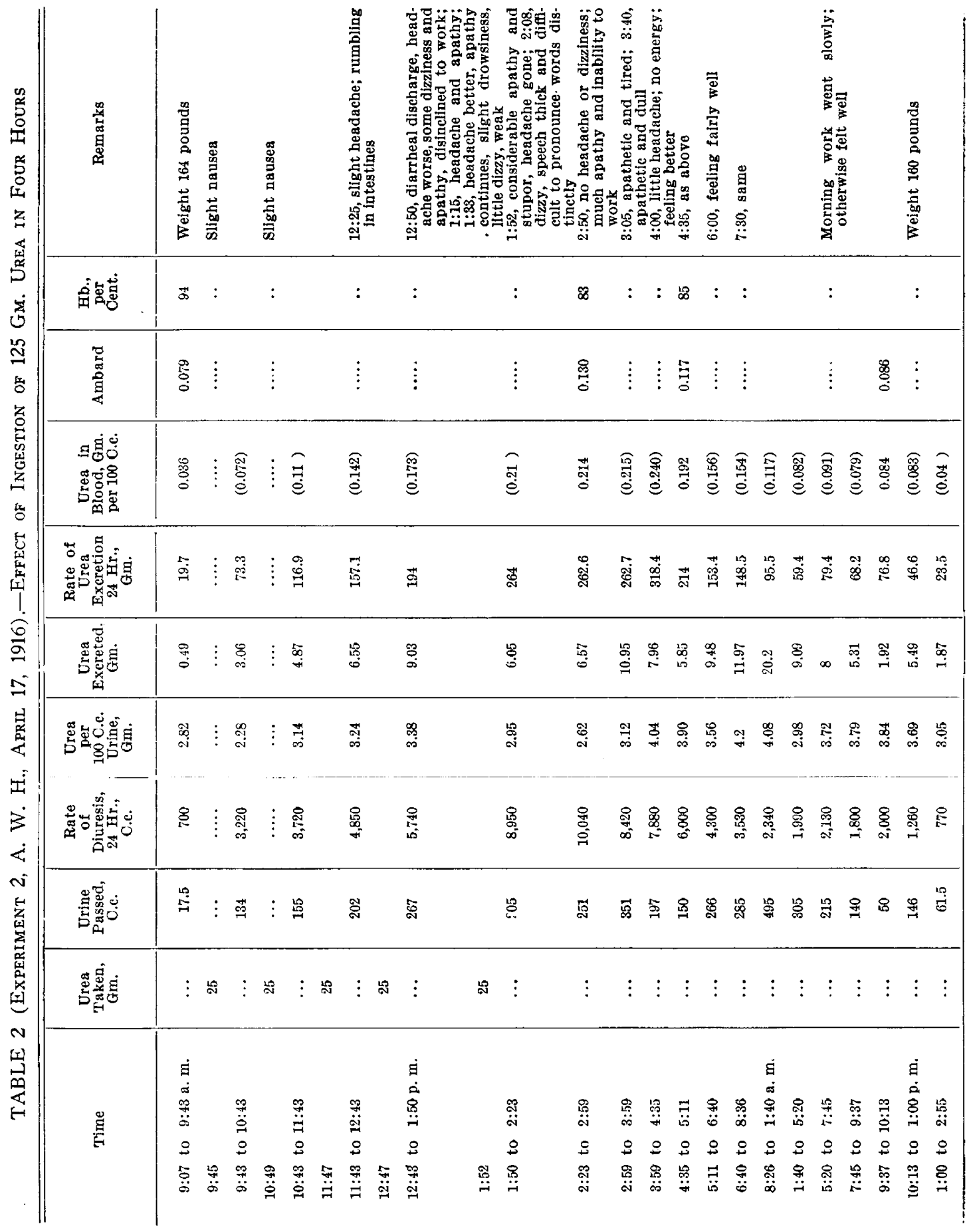




\begin{tabular}{|c|c|c|c|c|c|c|c|c|c|c|}
\hline 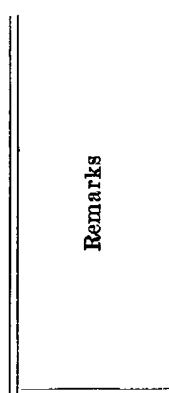 & 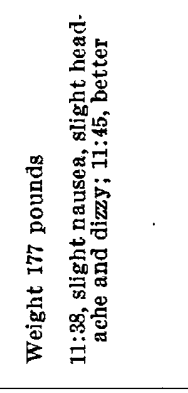 & 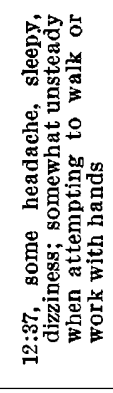 & 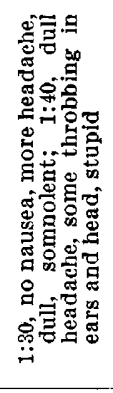 & 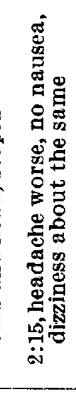 & 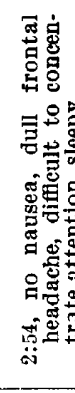 & 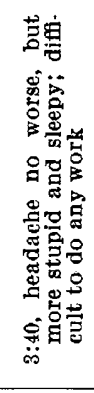 & 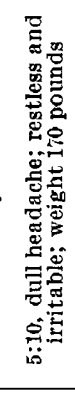 & 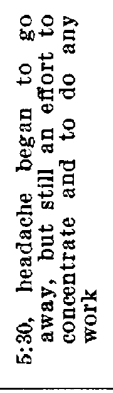 & 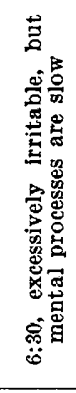 & 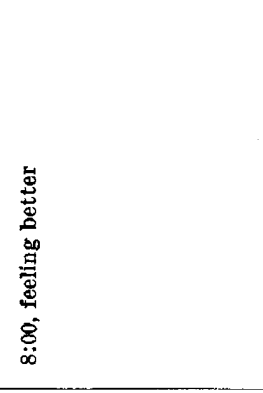 \\
\hline 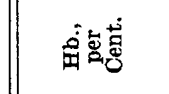 & $\approx:$ & $:$ & & $\therefore$ & $:$ & : & & $\varpi$ & & $\ddot{\circ}$ \\
\hline 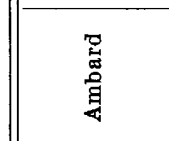 & 器 & $\vdots$ & $\vdots$ & 䒼 & $\vdots$ & $\vdots$ & & $\frac{\mathrm{g}}{\mathrm{a}}$ & $\vdots$ & 器 \\
\hline 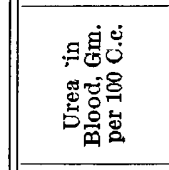 & 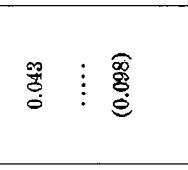 & 商 & छ્ฒ్ & 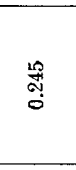 & 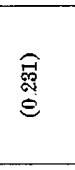 & 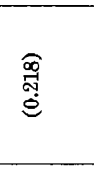 & 䕥 & $\frac{5}{8}$ & $\stackrel{\widehat{\underline{w}}}{\underline{\varepsilon}}$ & 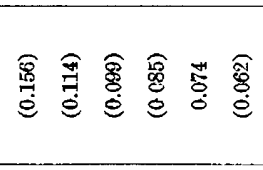 \\
\hline 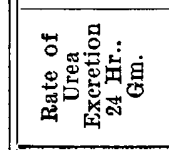 & \begin{tabular}{l:l}
$\overrightarrow{8}$ & $\vdots$ \\
\hdashline
\end{tabular} & 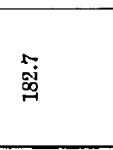 & 蒿 & 迥 & s. & $\ddot{g}$ & 递 & 通 & 落 & 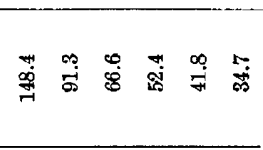 \\
\hline 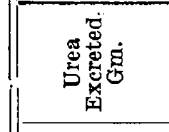 & 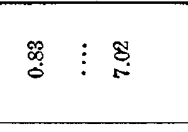 & $\stackrel{\infty}{\infty}$ & $\stackrel{5}{0}$ & $\stackrel{\infty}{\sim}$ & 煦 & $\stackrel{艹}{\ddot{0}}$ & बू & : & $\mathscr{\sharp}$ & 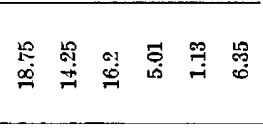 \\
\hline 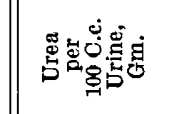 & 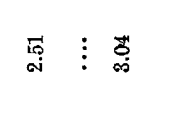 & 哭 & 昰 & $\stackrel{\leftrightarrow}{\stackrel{g}{+}}$ & 萜 & 8 & $\stackrel{8}{\$}$ & $\stackrel{8}{\sharp}$ & 跑 & 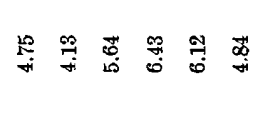 \\
\hline 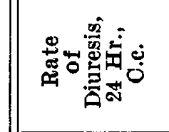 & \begin{tabular}{l:c}
8 \\
\hdashline
\end{tabular} & $\frac{8}{81}$ & 惫 & 疍 & 蛋 & 疍 & 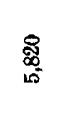 & 氶 & 承 & 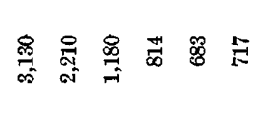 \\
\hline 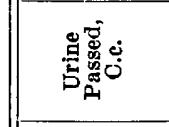 & œ $\vdots$ 喿 & $\mathscr{8}$ & 萬 & $\stackrel{\Phi}{9}$ & ฮ్ส & $\bar{g}$ & $\Phi$ & $\dot{\vec{D}}$ & 怘 & 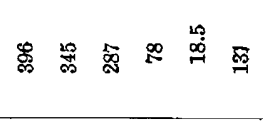 \\
\hline 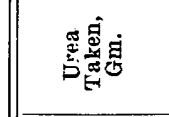 & $\vdots \vdots$ : & $\vdots:$ & $\vdots$ & $\vdots$ & $\vdots$ & $:$ & : & $\vdots$ & $:$ & $\vdots: \quad: \quad: \quad: \quad:$ \\
\hline : & 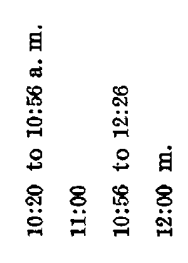 & 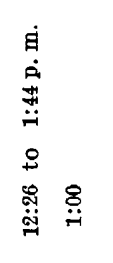 & 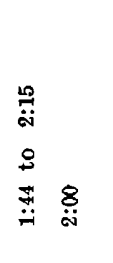 & 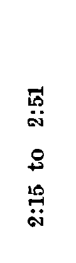 & 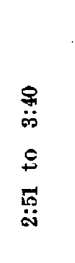 & 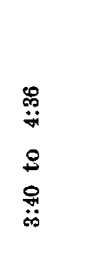 & 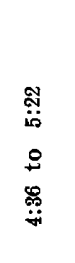 & 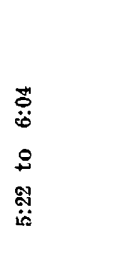 & 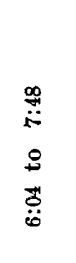 & 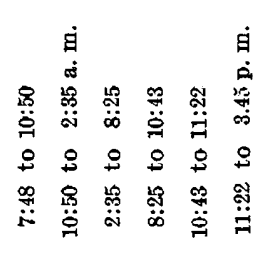 \\
\hline
\end{tabular}


once on the following morning. No restriction was placed on the exercise taken, the amount of water drunk or the amount or kind of food eaten.

The quantity of urea in the blood and urine was determined by Van Slyke's urease method. In the earlier experiments the final titrations were performed, using alizarin monosulphate as an indicator. At the suggestion of $\mathrm{H}$. H. Willard, however, methyl red was used as an indicator in one experiment (Experiment 2) and was found to give a more definite end reading. The hemoglobin in each specimen of blood drawn was determined by the Autenriech colorimeter. The results of our observations are shown in Tables 1 to 5 .

EFFECT ON UREA CONTENT OF THE BLOOD AND URINE

During these observations the amount of urea taken varied from 100 to $125 \mathrm{gm}$. In the first experiment 100 were taken within fifteen minutes, in the second $125 \mathrm{gm}$. were taken in $25 \mathrm{gm}$. doses at hourly intervals, in the third and fourth $100 \mathrm{gm}$. were taken in a similar manner, while in the fifth experiment $110 \mathrm{gm}$. were taken during six hours, the major portion being taken during the first three hours.

The effect of the ingestion was apparent in the first specimen of urine subsequently passed. This showed a more rapid diuresis and an increased excretion of urea. The rate of excretion rapidly augmented and reached a maximum within a few hours after the last dose had been taken. It was evident, therefore, that absorption from the gastro-intestinal canal was very rapid. At the height of the experiment the maximum rate of elimination of urea varied in the different experiments from 11 to $14.8 \mathrm{gm}$. of urea per hour. From this maximum the rate of elimination fell, at first rapidly and then more slowly. At the end of twenty-four hours it had approached but not reached the original rate. The amount of urea excreted within the twenty-four hours was greater than the amount ingested, but in view of the fact that the urea level in the blood had not yet returned completely to the normal at this time, it is fair to assume that the amount excreted in the twenty-four hours was somewhat less than the sum of what had been ingested and what had been formed in the body during this time.

The amount of urea in the blood as determined by direct analysis also reached a maximum within a few hours after the last dose had been taken. This maximum varied from 150 to $245 \mathrm{mg}$. per 100 c.c. of blood, indicating that we had attained our object of increasing the concentration of urea in the blood to amounts that were comparable with those encountered in the asthenic type of uremia.

According to Ambard, there exists, for any person, a constant 


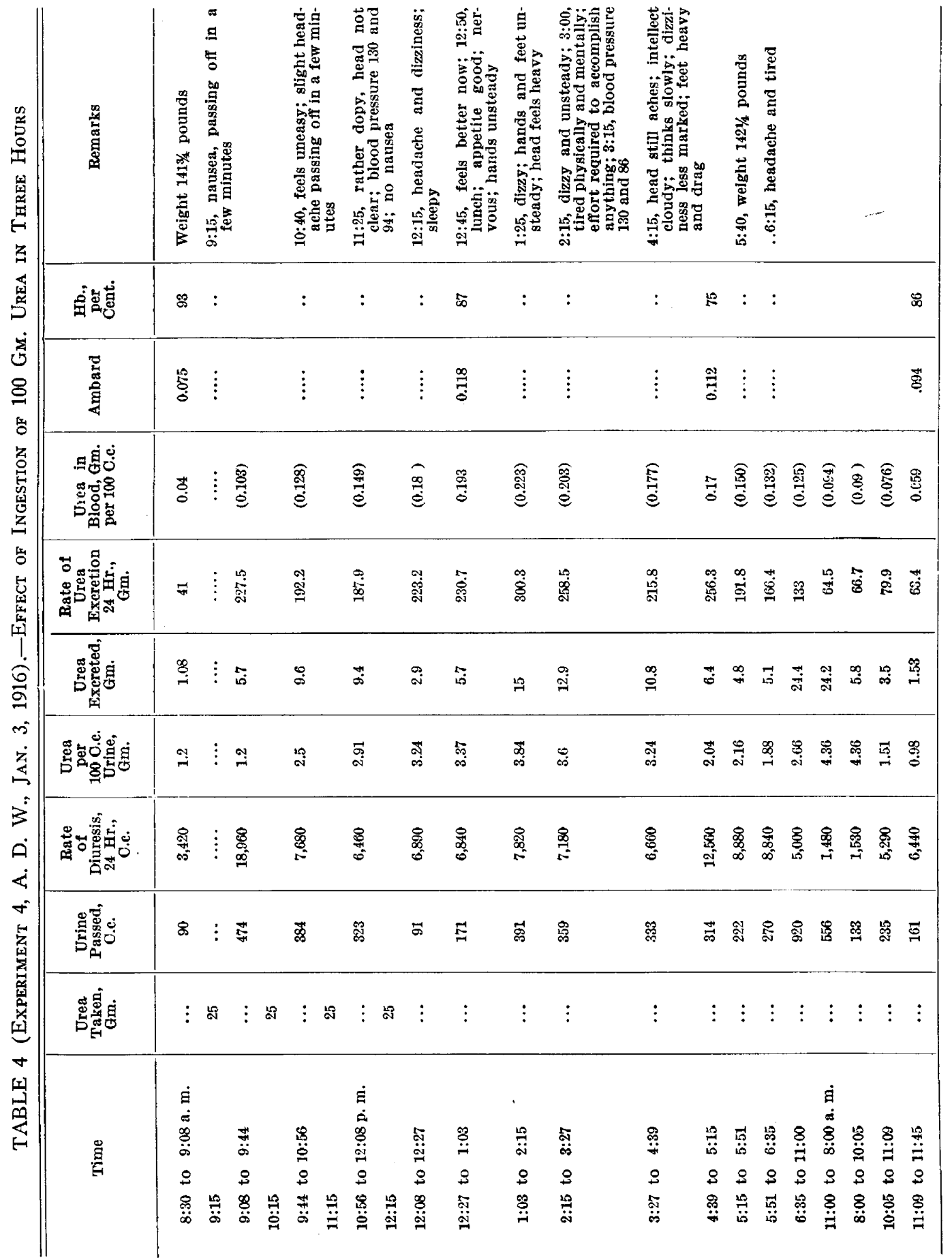




\begin{tabular}{|c|c|c|c|c|c|c|c|c|c|c|c|}
\hline 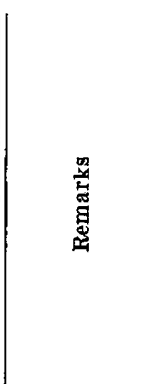 & & 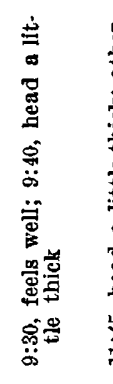 & 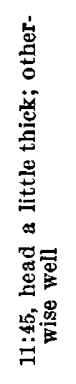 & & 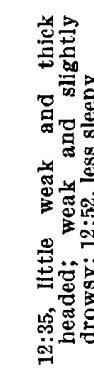 & 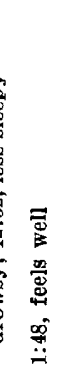 & 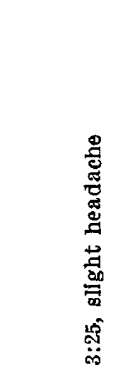 & 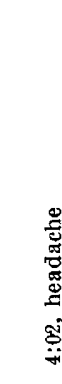 & & & \\
\hline 音能害 & $:$ & $:$ & $:$ & & $:$ & : & 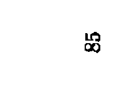 & & & & : \\
\hline $\begin{array}{l}\text { 总 } \\
\text { 章 }\end{array}$ & $\frac{9}{8}$ & $\vdots$ & $\vdots$ & & $\vdots$ & $\vdots$ & $\stackrel{8}{8}$ & $\vdots$ & & & 残 \\
\hline 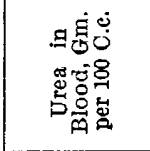 & 㬝 & 嫒 & 言 & 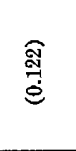 & 覚 & 佐 & 愛总 & & 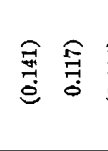 & & 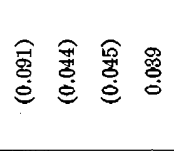 \\
\hline 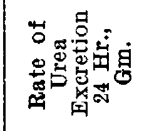 & $\stackrel{\infty}{\infty}$ & : & 递 & 边 & 总 & $\overrightarrow{\mathrm{x}}$ & 苑 & & 总泪 & & 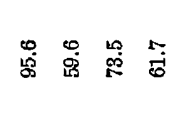 \\
\hline 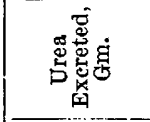 & : & i5 & $=$ & $\vec{j}$ & $\stackrel{8}{\circ}$ & $\stackrel{\infty}{N}$ & 욤 & $=$ & $\therefore$ & & 足 - 哭 \\
\hline 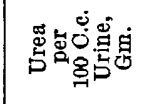 & $\underset{\$}{\$}$ & 范 & $\stackrel{\wp}{\sharp}$ & g & 器 & 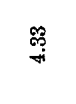 & $\stackrel{\infty}{*}:$ & $\infty$ & $¥ \%$ & & 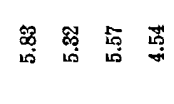 \\
\hline 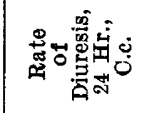 & $\stackrel{9}{7}$ & $8_{\infty}^{8}$ & 尊 & 苚 & 密 & 糔 & 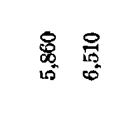 & 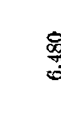 & 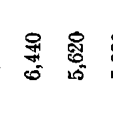 & & 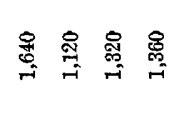 \\
\hline 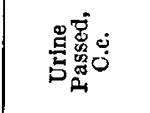 & 露 & $\Phi$ & $\stackrel{g}{g}$ & : & $\Phi$ & $\vec{\Phi}$ & $\stackrel{m}{\vec{s}} \underset{\sim}{\vec{p}}$ & สे & 욤 & & 昰然 \\
\hline 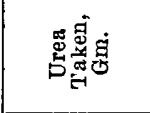 & $\vdots:$ & $\vdots$ & $\vdots$ \& & $\vdots$ & $=\quad \vdots$ & $\vdots$ & : : & & $\vdots:$ & & $\vdots: \quad: \quad:$ \\
\hline 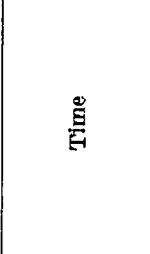 & 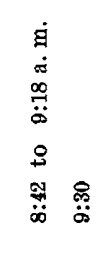 & 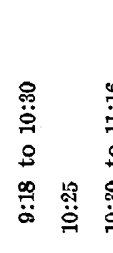 & 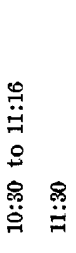 & 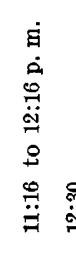 & 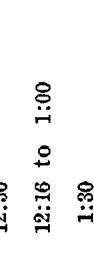 & 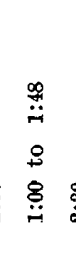 & 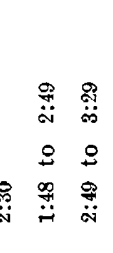 & 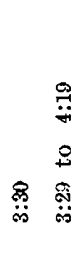 & 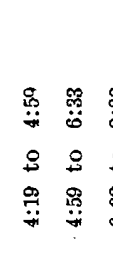 & & 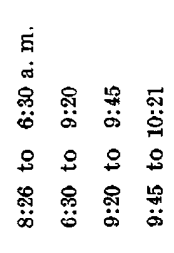 \\
\hline
\end{tabular}


relation between the concentration of urea in the blood and its excretion in the urine. Ambard's formula is as follows:

$$
k=\frac{U}{\sqrt{D \sqrt{\frac{\bar{c}}{25}}}}
$$

in which $U$ represents the number of grams of urea in 1,000 c.c. of blood, $D$ the output of urea over the observed period calculated for twenty-four hours, and $C$ the concentration of urea in the urine excreted, expressed in grams per liter. In the above experiments the Ambard factor $k$ was determined for each specimen of blood drawn. It was found to vary far less than any of the other data that enter into it, that is, the concentration of urea in the blood, the rate of excretion of urea and the diuresis. Nevertheless, the factor did not remain constant in any of the experiments, but regularly showed a rise when the urea concentration in the blood rose and a fall when the urea concentration in the blood fell. One might be inclined to interpret the rise of the Ambard factor during our experiments as an indication of renal fatigue, owing to the extraordinary strain placed on the kidney in the way of excreting urea. Against this interpretation, however, is the fact that the Ambard factor regularly fell during the afternoon of the experiment, although one would expect that here if anywhere the kidney would show signs of fatigue, owing to the continued excessive work. It seems to us probable therefore that the Ambard "constant" is but an approximation to the actual facts and that the kidney does not work with the mathematical precision that might be assumed from such a formula.

Nevertheless, we found the Ambard formula of considerable service in that by this means we were able to estimate the approximate concentration of urea in the blood at numerous points of our experiment. These estimations were made as follows. The determined points on the Ambard curve were connected by straight lines and the Ambard factor was assumed to correspond to the point at which these connecting lines crossed the time intervals. Having this assumed constant and knowing the rate of diuresis and the rate of urea elimination in the urine, we were able to estimate the approximate level of urea in the blood according to the following transposition of the Ambard formula:

$$
U=k \sqrt{D \sqrt{\frac{C}{25}}}
$$

in which the letters have the same significance as in the original formula. In this way the approximate level of blood urea could be interpolated at numerous points during an experiment. In the tables 
these interpolations have been enclosed in parentheses. The advantage of such interpolations is at once obvious when one endeavors to compare the onset and duration of symptoms with the concentration of urea in the blood at different times during an experiment.

\section{EFFECT ON WATER METABOLISM}

No restriction of fluid intake was carried out in these experiments and with one exception (Experiment 3) the fluid intake was not recorded. Although it was not possible to follow accurately the water metabolism in the body, nevertheless our observations indicate that the ingestion of such large quantities of urea is not without an effect on the fluids of the body. Considerable thirst was experienced during and for a time after the ingestion of the urea, and as the subjects were allowed to drink freely, considerable water was taken to satisfy this thirst. At the same time a marked diuresis accompanied the elimination of the large quantities of urea. The body weight varied according to the balance between the intake and the output of fluid. In Experiment 4 the subject drank very large quantities of water and gained $1 / 2$ pound during the day and lost $11 / 2$ pounds during the following night. In Experiment 3 the subject lost 7 pounds between the onset of the experiment and 5 o'clock in the afternoon. In Experiment 2, 4 pounds were lost in twenty-four hours and the original weight was not recovered for about four days. The changes in body weight were not recorded in Experiments 1 and 5.

TABLE 6.-EFfect on the Hemoglobin

\begin{tabular}{c|c|c|c}
\hline \hline Experiment & $\begin{array}{c}\text { Femoglobin } \\
\text { Before } \\
\text { per CCnt. }\end{array}$ & \multicolumn{2}{|c|}{ Hemoglobin After, per Cent. } \\
\cline { 2 - 3 } & 93 & $87,77,72$ & Next Morning \\
\hline 2 & $(93)$ & 83,85 & 92 \\
3 & 95 & 90,81 & 94 \\
4 & 93 & 87,75 & 86 \\
5 & 95 & 85 & 95 \\
\hline
\end{tabular}

During each experiment there occurred a definite fall in the hemoglobin, as is shown in Table 6 . This fall was usually most pronounced late in the afternoon of the experimental day, when the concentration of urea in the blood had already begun to fall. On the following morning the hemoglobin had returned more or less completely to the normal. Such a transient reduction in the hemoglobin indicates a dilution of the blood and since it also occurred even when the subject was rapidly losing weight (Experiment 3 ), the necessary liquids in such a case must have been withdrawn from the tissues. This dilution 
of the blood during the diuresis following these excessive quantities of urea is perhaps comparable to that which may occur after the ingestion of sodium chlorid or the saline diuretics. It probably played some part in provoking the diuresis in our experiments.

THE SYMPTOMS

Each subject noted his symptoms as they occurred. By comparing these notes with the concentration of urea in the blood at the time, it was possible to add to the objective character of the experiments and to determine to what extent the symptoms corresponded with an augmented concentration of urea in the blood. Experiment 5 differed from the first four, partly because the urea concentration did not reach the same high level and partly because the symptoms were less marked and not so definitely related to the maximum concentration of urea in the blood. For this reason it will be considered separately.

In all of the first four experiments some nausea was experienced after taking the first dose of urea, but vomiting did not occur. The nausea was most marked in Experiment 1, in which $100 \mathrm{gm}$. of urea were taken within fifteen minutes. In Experiment 2 it was present after the first three doses and was absent after the last two. In Experiments 3 and 4 slight nausea was experienced after the first dose, but none after the next three. In all cases the nausea had disappeared before the concentration in the blood had reached its maximum. It is evident therefore that in these experiments the nausea did not depend on a high concentration of urea in the body fluids or tissues, but was probably associated with local changes in the gastrointestinal canal. The subject of Experiments 1 and 2 had diarrheal evacuations of the intestines a few hours after the ingestion of the urea. The other subjects experienced no intestinal disturbances.

In each of the first four experiments definite symptoms occurred at the time that the concentration of urea in the blood was highest. Headache was first noted, the sensation usually being described as a tight feeling in the head or as a dull ache. This headache was soon followed by dizzy sensations, which were in turn followed by apathy, drowsiness and an inability to do the customary amount of work. Feelings of bodily fatigue and weakness occurred in each case. The subjects of Experiments 3 and 4, on whom fell the burden of the chemical determinations, were in each case unable to carry on this work during the afternoon which followed the taking of the urea, by reason of mental and bodily fatigue, together with an inability to concentrate the attention. In both instances the hands were unsteady. The subject of Experiment 3 became excessively irritable during the afternoon, while the subject of Experiment 4 complained particularly of bodily fatigue. In Experiment 2 at the height of the intoxication the subject found some difficulty in pronouncing words distinctly. 
These cerebral and bodily symptoms were most pronounced at the time of maximum concentration of urea in the blood. In all cases they appeared in a definite form at about the time that the blood urea reached a concentration of 150 to $160 \mathrm{mg}$. per 100 c.c. It is noteworthy that they appeared to be less intense at corresponding levels during the afternoon, when the amount of urea in the body was lessening.

The subject of Experiment 5 did not show so high a concentration of blood urea as did the other subjects. This was due in part to the fact that his ingestion of urea extended over a longer period. In part it was due to the fact that he showed an unusually rapid excretion, with an unusually low Ambard coefficient (increased renal permeability to urea). This subject complained at first of feeling somewhat thick headed, and later of being somewhat drowsy and disinclined to work. The latter symptoms coincided with the maximum concentration of urea in his blood (163 mg.). During the afternoon a headache developed, which gradually became more marked as the afternoon advanced and was quite intense at bedtime. During the niz̧t it disappeared. This subject suffers from occasional headaches (migraine?) and the experiment seems to have induced a headache of the usual type, but one of unusual severity. This headache was not due directly to the high concentration of urea in the blood, for it reached its maximum after the concentration in the blood had fallen below $114 \mathrm{mg}$.

In two experiments ( 1 and 4 ) the blood pressures were taken at the height of the intoxication, but in neither case was any marked hypertension present.

The symptoms observed at the maximum concentration of urea in the blood during our experiments correspond almost exactly with those described by Reiss for the asthenic type of uremia, that is, drowsiness and indifference, bodily fatigue and prostration. The loss of appetite described by Widal did not occur. On the other hand, headache and dizziness were quite constant. The symptoms observed developed at approximately the same level of blood urea in all subjects and this level corresponded roughly to that which is associated with definite and unmistakable symptoms in asthenic uremia.

To the analogy that has been drawn between the symptoms observed in these experiments and those of asthenic uremia, the objection might be raised that the symptoms observed after ingestion were due to the rapid entrance of urea into the tissues and that had the high level been maintained for some time the symptoms would have disappeared. This criticism is supported by the fact that the symptoms were usually more marked at a given level of blood urea when the urea was accumulating in the body than they were at the same level 
of blood urea when the urea in the body was lessening. It seems probable, therefore, that a portion of the symptoms observed may have been due to the acute character of the experiment. Nevertheless, the following facts indicate that the high level of urea in the body was responsible for the major portion of the symptoms. First, no definite symptoms occurred while the blood urea was rising from 40 to $150 \mathrm{mg}$. per 100 c.c., nor have symptoms been observed by other observers when from 20 to $30 \mathrm{gm}$. of urea have been given in a single dose. Second, the onset of symptoms occurred in each of our subjects when the level of blood urea had passed a definite point (about $150 \mathrm{mg}$.$) . Third, the symptoms, though less marked, persisted until$ the blood urea had fallen to approximately $160 \mathrm{mg}$. per 100 c.c. For these reasons we believe that the symptoms in our experiments were due, in the main, not to the sudden entrance of urea into the tissues, but to its high concentration therein.

It seems probable, therefore, that when as a result of nephritis the blood urea exceeds a concentration of $150 \mathrm{mg}$. per 100 c.c., the symptoms of bodily and mental asthenia may be explained in part as being due to the high concentration of urea in the body fluids and tissues. This by no means excludes the possibility that other substances may play a rôle in producing the symptoms of this type of uremia and indeed the fact that animals die only when extraordinary doses of urea are administered suggests that the fatal outcome of asthenic uremia in man may be due to other substances than urea.

\section{DISTRIBUTION OF UREA TO THE TISSUES}

It is well known that urea diffuses readily between the blood and the tissues. This fact is also apparent in our experiments. Assuming, for example, that there are 5 liters of blood in the body and that all of the urea administered remained in the blood, it would require but $10 \mathrm{gm}$. of urea to give a concentration of $200 \mathrm{mg}$. per 100 c.c. of blood. Since approximately $100 \mathrm{gm}$. of urea were required to raise the blood urea to this level, it is evident that the major portion of the urea ahsorbed from the gastro-intestinal canal must have passed rapidly from the blood into the tissues.

One may estimate roughly the additional amount of urea in the body at any time during our experiments, for this will equal the amount absorbed from the intestinal canal plus that formed by metabolism in the body and minus that eliminated through the excreta. For purposes of calculation we have assumed (1) that the urea was completely absorbed from the intestinal canal, (2) that it was eliminated entirely by way of the urine and (3) that the rate of metabolism was such that $1.5 \mathrm{gm}$. of urea were formed hourly in the body. If these assumptions are made, then the total amount of urea in the body 
at any time during the experiment may be estimated. Such estimations are shown in Table 7.

The various possible errors in the assumptions on which these calculations are based do not permit one to draw any definite conclusion as to the exact relation that exists between the amount of urea in the body and its concentration in the blood. It should be noted, however, that in the first two experiments diarrheal discharges occurred and that in this way a certain amount of urea was probably lost from the body. If this were the case, the estimated amount of urea in the body would have been less and the relation $(c)$ would have been greater. Similarly, in Experiment 5 and in the first estimation of Experiment 4 the blood was drawn about half an hour after the last dose of urea had been given. If one were to assume that this had not been entirely absorbed the excess in the body would again be less and the relation $(c)$ greater. It would appear, therefore, that for every gram of excess urea in the body the concentration of urea in the blood rose at least $2.5 \mathrm{mg}$. per 100 c.c. of blood.

TABLE 7.-Excess URea in the Body and Its Relation to THE EXcess iN THE BLOOD

\begin{tabular}{|c|c|c|c|c|c|}
\hline Experiment & $\begin{array}{l}\text { Body } \\
\text { Weight, } \\
\text { Kg. }\end{array}$ & $\begin{array}{c}\text { Time Since } \\
\text { First } \\
\text { Determina. } \\
\text { tion, } \\
\text { Hours }\end{array}$ & $\begin{array}{l}\text { Excess Urea } \\
\text { in Body, Gm. } \\
\text { (a) }\end{array}$ & $\begin{array}{l}\text { Excess in } \\
\text { Blood, Mg. } \\
(\text { b })\end{array}$ & $\begin{array}{l}\text { Relation } \\
b \text { to } a \\
(c)\end{array}$ \\
\hline 1 & 75 & $\frac{2}{4}$ & $\begin{array}{l}89 \\
72\end{array}$ & $\begin{array}{l}160 \\
\mathbf{1 2 0}\end{array}$ & $\begin{array}{l}1.8 \\
1.7\end{array}$ \\
\hline 2 & 75 & $\begin{array}{l}5 \\
71 / 2\end{array}$ & $\begin{array}{l}98 \\
77\end{array}$ & $\begin{array}{l}178 \\
156\end{array}$ & $\begin{array}{l}1.8 \\
9.0\end{array}$ \\
\hline 3 & 80 & $\begin{array}{l}4 \\
7\end{array}$ & $\begin{array}{l}79 \\
47\end{array}$ & $\begin{array}{l}202 \\
\mathbf{3 4}\end{array}$ & $\begin{array}{l}2.8 \\
3.1\end{array}$ \\
\hline 4 & 65 & $\begin{array}{l}4 \\
8\end{array}$ & $\begin{array}{l}76 \\
36\end{array}$ & $\begin{array}{l}153 \\
130\end{array}$ & $\begin{array}{l}2.0 \\
3.6\end{array}$ \\
\hline 5 & 78 & 6 & 54 & 113 & 2.1 \\
\hline
\end{tabular}

If $1 \mathrm{gm}$. of urea be uniformly distributed in a body weighing $70 \mathrm{~kg}$. it would cause an increase of concentration amounting to $1.4 \mathrm{mg}$. per $100 \mathrm{gm}$. It is evident, therefore, that while the major portion of the urea ingested entered the tissues, its concentration in the body as a whole fell considerably short of its concentration in the blood. Marshall and Davis ${ }^{2}$ have shown by chemical analyses that the urea concentration in certain organs and tissues of the body is approximately equal to its concentration in the blood. They found, however, that in the case of fat the urea concentration was low, and it seems probable that the same is true of the bones, the cartilages and possibly of other tissues. If one could allow for the low percentages in such 
tissues the urea concentration in the remaining tissues of our subjects may have approached that of the blood.

\section{CONCLUSIONS}

1. By giving approximately $100 \mathrm{gm}$. of urea by mouth over a short interval of time it is possible to increase the concentration of urea in the blood of normal persons to levels of from 160 to $245 \mathrm{mg}$. per 100 c.c.

2. At such levels of blood urea definite symptoms occur. These consist of headache, dizziness, apathy, drowsiness, bodily weakness and fatigue.

3. These symptoms are comparable to those encountered in the asthenic type of uremia.

4. For every gram of excess urea in the body there is a rise of concentration in the blood which approximates $2.5 \mathrm{mg}$. per 100 c.c. 